\title{
Early Turkish Immigrants' Adaptation to American Culture and Social Integration
}

\author{
BILAL SERT, Ph.D. ${ }^{1}$ \\ SEBAHATTIN ZIYANAK, Ph.D. ${ }^{2}$ \\ ${ }^{1}$ Texas Woman's University, Department of Social Sciences, Denton, Texas \\ 2 University of Texas of the Permian Basin, Department of Social Sciences, Odessa, Texas \\ (C) 2017 Bilal Sert, Sebahattin Ziyanak \\ This is an open access article distributed under the Creative Commons Attribution-NonCommercial-NoDerivs license \\ (http://creativecommons.org/licenses/by-nc-nd/3.0/) \\ DOI: 10.1515/eras-2017-0006
}

\begin{abstract}
Immigration studies still investigate immigrants' offspring and later generations' socioeconomic upward and downward motilities. When it comes to early Turkish immigrants, there is an unfilled "missing link" from a sociological point of view. This study explores early Turkish immigrants' adaptation experiences in the United Sates through qualitative triangulation and the methods of observation. This article utilizes "Straight-line theory", "decline theory", and "segmented assimilation to expound early Turkish immigrants' adaptation experiences in the United States. Drawing on archival documents next to meetings with immigrants' off springs, this study finds evidence that immigration occurred during the second wave to the United States from Europe, among Turks from Anatolia and Rumelia and they successfully adapted their new social environment. Rather, the findings provide novel evidence on the role of religious view and their social interaction. When seeking early Turks' socio educational background, we discover that highly educated individuals including religious leaders, professors, and businessmen migrated to Peabody, MA.
\end{abstract}

Keywords: Early Turkish Immigration, Adaptation, Ottoman Empire-Identity, Intermarriage-Millet, Muslim Turks, Greeks, Armenians, Sephardic Jews

\section{INTRODUCTION}

Sociologists, historians, and economists have been especially interested in the study of international migration because of its social, historical, and economic impact on both sending and receiving countries. The factors associated with European, Asian, Mexican, Latino, Cuban and African immigration waves and these immigrants' experiences in the United States have been explored in great depth in the international migration literature (Zhou, 1997;Portes and Min Zhou, 1993; Portes and Rumbaut, 2001; Piore, 1979; Massey et al.,1994; Macdonald and Macdonald, 1964; Gans, 1992; Gordon, 1961).

The main research problem in examining early Turkish immigration to the United Sates during the late 19th and early 20th centuries is a lack of academic resources. In addition to European immigration to the United States, the extant literature has also investigated Armenian, Greeks, and Jewish immigrants (Warner and Srole, 1945; Healey, 2012). These groups used to be called "Millet" (represent all racial, ethnic and religious groups Muslims and non-Muslims alike) during the reign of the Ottoman Empire. Muslims and Christians of Anatolia and Rumelia* had shared common life experiences for a long time. Armenians, Greeks and Turks lived the same communities in the United States as they had in Anatolia and Rumelia, and they shared similar social and economic experiences. This study aims to fill this gap by addressing what the early Turkish immigrants' adaptation experiences in the United States were.

Despite the fact that a few Turkish historians have paid attention to this topic (Karpat 1985, 1995; Acehan, 1995), sociological treatment of early Turkish immigration is scant. This study employs international migration and adaptation theories to explain the dynamics of Turkish immigration to the United States in the late 19th and early 20th centuries. Whether Turkish immigration is explained by the extant immigration and adaptation theories of sociology or not, the outcome is unique since no one has paid attention to explaining early

*Anatolia was the Asian and Rumelia was European side of the Ottoman Empire 
Turkish immigration to the United States from a sociological point of view.

Finally, early Turkish immigrants' offsprings' narratives have confirmed almost all information obtained from collected data. There are some of early Turkish immigrants' offsprings who reside in the United States with their children and grandchildren in places like Rhoda Island, Maryland, Illinois, New York, New Jersey, Ohio, North Carolina, New Hampshire and Massachusetts. It is possible to find traces of early Turkish immigrants in these communities. We have tried to support descriptive and explanatory literature on this issue through contacting the offspring of these immigrants spread over the eastern seaboard of the United States.

\section{Adaptation Experiences}

The total number of Millet immigrants from the Ottoman Empire was about 400,000. However, only 25,000 to 50,000 of these immigrants were Muslim Turks, and since some assumed they might suffer potential religious discrimination in the United States; they registered under Christian names at the port of entry. Also, many of them registered as Syrians and Armenians in order to gain easy entry. This raises the possibility that the Turkish names of the immigrants may be more complex than they appear to be. Karpat (1995) indicates that the majority of Turks entered the United States via seaports in Providence, Rhode Island, Portland, and Ellis Island. He also mentions factors accelerating Turkish immigration from Anatolia involving French shipping agents, the Missionary American College in Harput (a south-eastern city in Turkey), and the French and German schools, which encouraged Millet immigration from the Anatolia.

"Straight-line theory", "decline theory", and "segmented assimilation theory" are three competing theories used to describe European immigrants' and first immigrants' off springs' adaptation experiences in the United States. We incorporated these theories in the present study in an effort to explain early Turkish immigrants" adaptation experiences in the United States. The "straight-line" theory is a pioneering theory in the field. In the article entitled "The Social Systems of American Ethnic Groups" Warner and Srole (1945) originally presented the straight-line theory. They focused on Irish, French, Canadian, Greek, Jewish, Polish, Armenian, and South Italian groups and their experiences in the United States. Since Greeks, Armenians and Turks clustered around the same spaces in the Ottoman Empire, we took this theory into consideration. The authors examined the first-comers, their offspring, and later generations. They mention the straight upward mobility of these groups, but on different levels. In straight-line theory, we see the process of upward mobility without any exception for all these groups. In other words, all move up, but to different extents.

Furthermore, "Segmented assimilation" theory (Portes and Rumbaut, 2001; PorteS and Zhou, 1993; Zhou, 1997) argues that the children of immigrants assimilated different from the single straight-line proposed by Warner and Srole (1945). There are three different possible outcomes for immigrants; the children of middleclass immigrants will move up by using the resources linked to their parents' class and the opportunities furnished by American education "slated for a smooth transition into the mainstream" (Portes and Rumbaut, 2001:45), the children of low-skilled immigrants, on the other hand, will face lack of opportunities and move down, finally some of these groups will move up economically, but will move down culturally.

Other international migrations alike, there is not a single theoretical perspective explaining early Turkish immigrants' adaptation experiences in the United States. In this study, we focus on these theories into the current study to answer the present research question. Actually, we emphasizes the importance of all these theories to guide us during the data collection and data analysis processes because of the fact that there is a lack of sociological treatment about this neglected international migrant population. As for adaptation experiences, the "segmented assimilation theory" outshone the others in predicting early Turkish immigrants' adaptation experiences in the United States.

\section{METHOD}

In this study, we used qualitative triangulation: methodological, theoretical, and environmental triangulation. In the qualitative method approach, increasing reliability and validity depends on using multiple measurements or multiple qualitative methods, and benefiting from multiple theoretical approaches and collecting data from multiple regions. Triangulation is beneficial in social research in terms of "increasing confidence in research data, creating innovative ways of understanding a phenomenon, revealing unique findings, challenging or integrating theories, and providing a clearer understanding of the problem" (Thurmond, 2001, p. 254).

First of all, this study employs an unobtrusive comparative and historical research method. As a part of the comparative and historical research we used archival record analysis. This strategy is a powerful tool especially when it comes to analyzing a society and its historical facts, but "observers must be sensitive to the selective bias introduced by the person preparing such reports" (Denzin 1978, p. 264). This method employs the 
word comparative because social scientists - in contrast to historians who may simply describe a particular set of events - seek to discover common patterns that may re occur in different times and places" (Babbie 2007, p. 319).

Moreover, we used oral historical reports of early Turkish and Greek immigrants' offspring residing in multiple states in the United States as a part of environmental triangulation. Beside libraries, we benefitted from the local historical societies of cities in Massachusetts, Rhode Island, New Jersey, and New York where a majority of early Turkish immigrants firstly settled. We visited Turkish and Muslim institutions in Worcester, Boston, Peabody, and New York to meet people to hear their stories. We compared these stories with archival data, biographies, stories, pictures, newspaper articles, and the Ottoman and English written pieces regarding early Turkish immigrants.

The data were collected between December 2013 and March 2014. As a pivotal component of this study and the main data source, Ahmed Emin's (1912) article was transcribed into modern Turkish and translated into English for the first time. Also, the information the article contained was used as both a main archival source and a standpoint for further data pursuits. For instance, the article addressed the cities where the data were collected. Also, the article mentioned very important information about early Turkish immigration, initiating factors and adaptation experiences, which we confirmed or challenged throughout this study based on the other collected data.

When we started searching libraries and online databases we noticed that libraries treat all materials written in Arabic Letters as Arabic documents, but in fact, other languages can be written in Arabic letters. Although Arabic and the Ottoman languages can be easily discerned, almost all documents written and printed in the Ottoman language are treated as Arabic scripts. Many librarians on the East Coast cities failed to recognize the existence of the Ottoman Language. If one considers the libraries holding thousands of pieces recorded as Arabic scripts, one may understand how difficult it is to eliminate these pieces in order to obtain specific documents, pictures, and the Ottoman scripts written in Arabic letters.

\section{FINDINGS}

The data are gathered to address to the following questions: To what extent did early Turkish immigrants culturally adapt to the American Society in their earlier and later times? How did their religious and cultural affiliations impact their lives? Can we characterize Turkish immigrants' first adaptation experiences: as adaptation, or as assimilation? How the later generations sustained their immigrant legacy? What were the main factors shaping their social interactions with American Society? According to this research, early Turkish immigrants' adaptation experiences can be understood in three main distinct categories:

1) Early Turkish immigrants' expectations from the United States.

2) Sociopolitical events at both the global and national level.

3) The American society's reactions to Muslim Turkish immigrants.

The present data are classified and analyzed based on these three areas of investigation. Wherever possible, we tried to confirm the archival and scholarly information by early Turkish immigrants' offsprings' narratives. In that sense, our aim was to increase the reliability of the data. Also, we related micro and macro sociological theories of international migrants' adaptation to the passages from articles, stories and pictures, and the other collected data to shed light on early Turkish immigrants' everyday life experiences in the United States.

Early Turkish immigrants, just like the other races and ethnicities immigrated during the second wave, had numerous cultural and financial challenges. The first and foremost priority, the immigrants' first experiences were comprised of adjusting to the American life by working in multiple jobs in order to survive.

Ahmed Emin (1912) compared urbanized and educated early Turkish immigrants adaptation experiences with other educated urbanized racial and ethnic groups. For Ahmed Emin, since the numbers of Turkish immigrants were limited and they spent less time here, conclusions based on this comparison could be unreliable. As for those who migrated from the rural areas to the United States, their numbers were greater than those who migrated from urban areas and they lived in specific places together. In that sense, it is possible to compare their adaptation experiences with the other racial and ethnic groups in terms of the following:

1) How well they adapted to their new environment?

2) How were they exposed to the new social environment?

3) Were they able to establish cultural or religious institutions in the United States?

Turkish immigrants' daily life choices and occupational inclinations force them into interacting with the American Society. For instance, everyday routines, socioeconomic improvements, and social interactions of those working in the railroads were the same as factory workers. "Since they moved frequently, their residence was limited to living in wagons each of which contained a bed, table, and stove, just elementary needs. They transformed wagons into homes. Headworkers were all Turks. Because they were located in the midst of rural areas, they lived like villagers. Even though they went to Chicago weekly, they are inured to city life's 
attractions" (Ahmed Emin 1912:6). For Ahmed Emin, those who opened their own businesses interacted with American society more frequently and adapted into mainstream culture to a greater extent than factory and railroad workers.

According to the offsprings' narratives, Greek and Armenian friends played significant roles in each stage of the early Turkish immigration settlement from the decision making process to immigrate to the New World, hosting the immigrants after their entry, and helping them out in terms of adaptation practices. For instance, Greek friends provided Greek passports for many Turks for easy entry and became a good company during this long journey. A Greek lady, owner of a Pizza place, had been residing in Worcester since 1950's. She confirmed this friendship among the Turks and Greeks in Worcester and nearby cities in MA. She said that this friendship still continued and that the chef working in her restaurant for 40 years was a Turkish man and he was her family's best friend. They all still speak fluent colloquial Turkish and watch Turkish TV channels on satellite TV. They follow news and TV shows from Turkey. We chatted about the TV shows and politics for a while and we are impressed that they know about ongoing incidents in Turkey than wedo. However, she also mentioned that the Armenian attitudes toward Turks sharply changed in a negative direction after the political turmoil (1915 Incidents) between the Armenians and Turks in Anatolia. She strongly recommended me not to talk to any Armenian in Worcester, saying, "They may harm you".

Oral record confirms long lasting friendships among the Millets in the United States. As early Turkish immigrants' off springs narrated, Greeks participated in Turkish Independent Day Balls organized annually in New York City. In the late 1930s, Greek friends helped early Turkish immigrant groups to rent space in YMCA/NYC (Young Man Christian Association in New York City) for cultural activities. One of our informants, was born in 1932, and is currently residing in Phoenix. He is a WWII Veteran from US Navy. Mr. K.N. shared the picture taken in at the YMCA/NYC where early Turkish immigrants' offsprings were taking Turkish Language courses, music, and folkloric dance classes in the late1930's and early 1940's.

In their first years, however, early Turkish immigrants were not interested in cultural activities. "It is very important to mention that there is a museum in which there are exquisite pieces and goods brought by ship captains from different countries and there is even a Turkish section in this museum. Even though this museum is open on Sundays, Turkish immigrants are not interested in visiting it at all as opposed to other migrant workers who enthusiastically visit it. However, no one knows any Turk had visited this museum" (Ahmed Emin 1912, p. 8). Ahmed Emin narrated immigrant Turks adaptation experiences only in Peabody, which does not necessarily reflect the other immigrant Turkish adaptation. For instance, Turkish immigrants in Worcester, sixty miles away from Peabody, MA, were socially active in the American Society. They established two institutions and became part of the significant cultural elements of Worcester society even after sociopolitical turmoil among the Millets emerged. Even though the majority did not marry, they left their footprints behind. They succeeded in contributing to the American Society.

Early Turkish immigrants' adaptation experiences in Worcester are a significant element in our research. We initiated our research from Worcester and benefitted from its "historical society" resources, which allowed me to address the three categorizations of early Turkish immigrants' adaptation process in the United Sates. In our Worcester visit, we went to the Hope Cemetery where there is Muslim Turkish land purchased by the Muslim Brotherhood Association established in Worcester, MA in 1918. There are 231 early Turkish immigrants buried in Hope Cemetery, and there are six more places already purchased by the offsprings still living in the United States. The cemeteries are well taken care of. The tombstones have Arabic scripts, crescents, and the star image clearly indicates the Turkish heritage. We visited nearby cities, obtained vital records, and found more graves belonging to early Turkish immigrants in almost 40 cities; however, nowhere else is the cemetery as organized as the cemetery in Worcester, MA since Turks formed durable institutions in Worcester creating the the first Muslim organization in the United States: The Muslim Brotherhood Association in 1918.

The first claim seems reasonable for many immigrant Turks, but this is only a small part of big picture. The sociopolitical conflicts such as Balkan Wars, WWI, social turmoil among the Millets in the United States and tension in the American Society that emerged after these events can be other reasons for return migration. According to offsprings' narratives, Frank Ahmet (1983) and Ahmed Emin (1912) assessments, the relationship among the Ottoman Millet residing in the same cities and neighbourhoods was seriously impacted, but some remained friends ${ }^{\dagger}$. Frank Ahmet (1983) pointed out that when the United States entered WWI in 1917 , "hostilities against immigration and natives intimidations reached a peak in the American Society. Thus, the Turkish immigrants were placed in the position of coping with antipathies from numerous sides, which sharpened Turks fiery character. Life became miserable for many immigrant Turks. Tension was high and resulted in street fights on many occasions". Local newspapers and police reports demonstrate that there were

\footnotetext{
$\dagger$ This friendship even after these events have been mentioned by almost all Turkish and Greek offsprings
} 
several social incidents in Peabody. We also discovered newspaper articles showing great hostility against Muslim Turks in Worcester as well as in nearby cities.

\section{Language}

In terms of language, offspring of the early Turk immigrants who kept their connections with their homeland are still be able to speak Turkish. Those who lost that connection are not able to speak fluent Turkish, but still understand it quite well. As for the offsprings' children and grandchildren, they are not able to speak or understand Turkish at all which is the rule that affiliated to the third generation of every ethnic group that immigrated to the United States.

\section{Work}

In terms of socioeconomic improvement, on the one hand, it was mostly working class Turks who immigrated to the United States during the second wave. Some succeeded financially, but could not find a place in mainstream culture because of the three categorizations indicated earlier. Here are the passages from Ahmed Emin's (1912) piece indicating that some succeeded financially in the United States.

Some opened businesses and some occupy higher positions in their workplace. Mustafa Aga, for instance, emigrated from one of Harput villages, resides in Worcester and came from Turkey 15 years ago (Approximately 1895), owned a wonderful butcher store and an ice-cream shop in one of the best American neighbourhoods. His workers speak Turkish and fluent English, and dress very well. In addition, Mustafa Aga's nephew work in iron string factory for 8 years and was promoted to administrative position earning more than 30\$/week (p.10).

\section{Religion}

Married early Turkish immigrants were adapted, and partially assimilated into the American Society. They became Americanized while keeping vestiges of Turkish and Islamic identity. However, they were still sensitive in the context of their religious beliefs. Even though some of offsprings' mothers were Christian, children attended both religions' celebrations and services in their childhood. Off springs, and their kids, and their grandchildren are still Muslim at a symbolic or secular level even though some were raised by Christian mothers.

Listening to some of offsprings' narratives, we were able to measure early Turkish immigrants' off springs' religiosity. We concluded that all hold Islam as a religious identity at a symbolic level. Based on the findings, Muslim Turks' offsprings who stayed in the United States have considered religion as a priority in their social interactions. Another piece of supportive evidence for this notion is that many offsprings joined the U.S. army during WWII. This situation indicates a strong attachment to the American Society among the offsprings and of course their children and grandchildren, some of whom joined the U.S. army as their fathers.

Not only having darker skin, but also having Islam as a religious identity must be taken into consideration in explaining both historical and contemporary immigrant adaptation experiences in the American Society. Other groups of immigrants' religious affiliation have been studied in great depth (Healey, 2012). The religious preference of early Turkish immigrants is hence a neglected significant explanatory variable according to the present data. It must be noted that tragic 9/11 increased offsprings religious awareness. An offspring, who is WWII veteran, told that "I fought in the American side and I am proud of it. But, the things happened to Muslims after 9/11 hurtled me a lot".

According to our investigation, some of early Turkish immigrants' offsprings, their children, and grandchildren still reside in almost all the states in the United States. Therefore, more investigation in this realm is needed. For instance, in the time frame of 45 minutes, we noticed 25 cemeteries in which some of early Turkish immigrants were buried, but their numbers are far less than their actual number. Many of them died alone at young ages. Some married having grandchildren who don't know anything about their Turkish ancestors. In Worcester, for instance, a young man named MO (Short version of Muhammed) is still searching for his ancestors in Turkey. He drew a crescent and star on his car's plate (in the form of Turkish Flag), which is the same as that seen on Turkish tombstones in the Hope Cemetery, Worcester, MA. That is all he knows about his Turkish heritage. Consequently, early Turkish immigrants' offsprings and the second generations' adaptation should be qualitatively and quantitatively investigated in future research. 


\section{CONCLUSION}

Using the methodological, environmental, and theoretical triangulation to increase validity and reliability of the data, this article applies the adaptation theories to explore Early Turkish immigrant's adaptation process in the U.S. We have not only relied on archival documents in our research. Instead, wherever possible, we confirmed our findings with early Turkish and Greek immigrants' offspring narratives, first person narratives, vital records, online stories, travelogues and historical monographs. For instance, this study found thatAhmed Emin's (1912) statements with archival documents, vital records, off spring narratives, other travelogues, online stories, novels, and historical monographs. Building may arguments based on Ahmed Emin's study, we both agreed and challenged with his arguments.

We have not found any official census reports or scientific study proving this in the literature. However, one of unique aspects of this study is that we have searched cemetery records and obtain information about less than 500 early Turkish immigrants' cemeteries in different locations in the United States. Even if we rely on the lowest number claimed by the extant studies and First World War military registration draft list and compare that to the number of graves we have surveyed in all of the cities where the first generation Turks settled, Peabody, Lowell, Chicago, Providence, Manchester, Worcester, and Boston, we arrive at a number below 500 even if we multiply that number by a factor of 10 to account for graves undiscovered we will have to admit that well over $2 / 3$ of this generation have returned to their homeland. According to our investigation, some of early Turkish immigrants' offspring, their children, and grandchildren still reside in almost all states in the United States. Therefore, more investigation is needed regarding early Turkish immigrant population immigrated to the United States in the late 19 th and early 20 th centuries.

Third, this population created religious and national charitable organizations within a short time of its arrival including the first Islamic Association in the United States, "Muslim Brotherhood Association of Worcester, MA founded in 1918" and "Angora Orphan Aid Association", "Hamiyetli Gencler" Detroit in 1925 (Public-spirited Young Turks in Detroit), and "Turkish Culture Alliances" (Turk Hars Birligi) in New York in 1933. They also participated in erecting the Turkish exhibit in Chicago's "World Fair" in 1893.

Forth and the most important is the documented case of massive return migration for the early Turkish immigrants. As mentioned before by the early researcher (Ahmed Emin, 1912), 40,000 Turks immigrated to the United States. Immigration files in the American entry ports reported 26,000 Turks entering the United States. The evidence discovered for Turkish men is regarded uncovered approximately 18,000 Turkish men's registrations for military draft to enter the United States' military forces by Turkish born men. Even if we rely on the lowest number in this list and compare that to the number of graves we have surveyed in all of the cities where the first generation Turks settled, Peabody, Lowell, Chicago, Providence, Manchester, Worcester, and Boston, we arrive at a number far below 500 even if we multiply that number by a factor of 10 to account for graves undiscovered we will have to admit that well over $2 / 3$ of this generation have returned to their homeland. 


\section{REFERENCES}

Ahmet, F. (1983). Turks in America: The Ottoman Turk's immigrant experience. New York: Columbia International.

Acehan, I. (2005). Outposts of An Empire: Early Turkish migration to Peabody, Massachusetts, Master thesis submitted to the Institute of Economics and Social Sciences of Bilkent University, Ankara.

Babbie, E. (2007). The practice of social research. CA: Thomson Wadsworth.

Denzin, Norman K. 1978. The research Act: A theoretical introduction to sociological methods $\left(2^{\text {nd }}\right.$ ed.). New York: McGraw-Hill.

Gans, H. (1992). Second generation declines: Scenarios for the economic and ethnic futures of post-1965 American immigrants. Ethnic and Racial Studies, 15:173-192.

Gordon, M. (1961). Assimilation in America: Theory and reality. Daedalus,90(2): 263-285.

Healey, J. (2012). Race, Ethnicity, Gender, and Class: The sociology of group conflict and change. 6th ed. Thousand Oaks, CA: Pine Forge Press.

Karpat, K. H. (1985). The Ottoman emigration to America, 1860-1914.International Journal of Middle East Studies, 17: 175-209.

Karpat, K. H. (1995). The Turks in America. Les Annales de l'Autre Islam 3:231-52.

MacDonald, J. S., and MacDonald, L. D. (1964). Chain migration ethnic neighbourhood formation and social networks."The Milbank Memorial Fund Quarterly, Vol. 42, No. 1, pp. 82-97.

Massey, D., Goldring, L., and Durand, J. (1994). Continuities in transnational migration: An Analysis of nineteen Mexican communities. American Journal of Sociology,99(6): 1492-1533.

McCarthy, J. (2010). The Turk in America. The University of Utah Press.

Piore, M. J. (1979). Birds of passage. Migrant labour and industrial societies. New York: Cambridge University Press.

Portes, A., and Zhou, M. (1993). The new second generation: Segmented assimilation and its variants. Annals of the American Academy of Political and Social Science, 530: 74-98.

Portes, A., and Rumbaut, R.(2001). Legacies: The Story of the immigrant second generation. Ch.3 (pp. 44-69), Not everyone is chosen: Segmented assimilation and its determinants. Berkeley: University of California Press.

Thurmond, V. (2001). The point of triangulation. Journal of Nursing Scholarship, 33(3), 254-256.

Warner, W. L. and Srole, L. (1945). The Social systems of American ethnic groups. Chapter 2 (pp. 30-32) Methods for the Study of Ethnic Groups and Ch.5 (pp. 67-102). New Haven: Yale University Press.

Yalman, A. E. (1912). Amerika ya Turk muhacerati. Istanbul Universitesi Edebiyat Fakultesi Mecmuasi, No 1.

Zhou, M. (1997). Segmented assimilation: Issues, controversies, and recent research on the new second generation. International Migration Review, 31(4): 975-1008. 